\title{
Differential release of superoxide anions by macrophages treated with long and short fibre amosite asbestos is a consequence of differential affinity for opsonin
}

\author{
I M Hill, P H Beswick, K Donaldson
}

\begin{abstract}
Objective-To investigate the ability of short and long fibre samples of amosite asbestos to stimulate superoxide production in isolated rat alveolar macrophages, and to determine how opsonisation with rat immunoglobulin might modify this response.
\end{abstract}

Methods-Macrophages were isolated from rat lung by bronchoalveolar lavage and challenged with both opsonised and non-opsonised long and short fibres of amosite asbestos. Release of superoxide anions was measured by the spectrophotometric reduction of cytochrome $c$, in the presence and absence of superoxide dismutase.

Results-Both long and short fibre samples of amosite asbestos without opsonisation were ineffective in stimulating isolated rat alveolar macrophages to release superoxide anions in vitro. After opsonisation with immunoglobulin, however, a dramatic enhancement of release of superoxide anion was seen with long fibres, but not short, which confirms the importance of fibre length in mediating biological effects. The increased biological activity of the long fibre sample is explained by increased binding of the opsonin to the fibre surface as, at equal mass, the long fibres bound threefold more immunoglobulin than the short fibres.

Conclusion-Opsonisation is an important factor in modulation of the biological activity of fibres at the cellular level. Differences in binding of opsonin to samples of fibre previously considered to be identical apart from length, suggest that surface reactivity needs to be taken into account when fibres are compared. Binding of biological molecules, in vivo, may thus be an important modifying factor in the pathological processes initiated by fibres.

Department of Biological Sciences, Napier University, Edinburgh

I $M$ Hill

P H Beswick

K Donaldson

Correspondence to:

I M Hill, Department of

Biological Sciences, Napier

Biological Sciences

University, Merchiston

Campus, 10 Colinton Road

Edinburgh EH10 5DT.

Accepted 29 September 1994 not fully understood. The concept that reactive oxygen species may underlie the pathogenesis of derangement has become the focus of extensive research in recent years. ${ }^{1}$ There are two potential sources of oxidation; the fibres themselves, ${ }^{2}$ and the reactive oxygen species produced by inflammatory leucocytes recruited to the sites of fibre deposition. Our study focuses on the reactive oxygen species.

It is known that oxidants derived from phagocytes play a critical part in the host's defence but, accumulating evidence indicates that damage caused by their inappropriate release, can contribute to the development of many types of lung disease. ${ }^{3-5}$ Various mechanisms have been proposed by which fibres may induce such production. ${ }^{67}$

It has been suggested that the release of reactive oxygen species in response to long fibres may be the result of frustrated phagocytosis on the part of the alveolar macrophage ${ }^{8}$ or is a direct result of stimulation of NADH or NADPH oxidase when the asbestos fibre interacts with the macrophage cell membrane. ${ }^{4}$ Conversely, it may be an as yet undefined combination of the two. Roney and Holian have suggested that phospholipase $C$ is involved in activation of the protein kinase $C$ to stimulate generation of superoxide anions, ${ }^{7}$ and Kalla et al have also shown that extracellular calcium prolongs this release. ${ }^{9}$

Most of these studies have been carried out with chrysotile and crocidolite asbestos fibres. Both of these types of asbestos have been shown to induce the production of superoxide radicals from alveolar macrophages of the hamster, rat, ${ }^{410}$ guinea pig, ${ }^{79}$ and human. ${ }^{11}$ Long chrysotile fibres have been found to be more effective than short fibres in eliciting release of superoxide anions from rat alveolar macrophages. ${ }^{5}$

Macrophages interact with their environment through the binding of molecules to receptors on their external surface. ${ }^{12}{ }^{13}$ In general, such interaction with a foreign particle will lead to phagocytosis, but optimum ingestion is mediated by proteins derived from the host, which coat the foreign material and thereby increase its recognition by phagocytes. Various soluble components, present in the bronchoalveolar space, have been shown to be opsonic in this way, including immunoglobulin (IgG). In the presence of IgG, superoxide generation induced by asbestos is significantly enhanced in macrophages of guinea pigs ${ }^{14}$ and humans. ${ }^{11} 15$

In phagocytosis mediated by opsonins, the opsonins serve as a ligand, which can attach the xenobiotic to its receptor on the phagocytic membrane. Binding of the ligand to 
Figure 1 Size distribution of short and long amosite samples based on phase contrast optical microscopy of over 400 fibres.

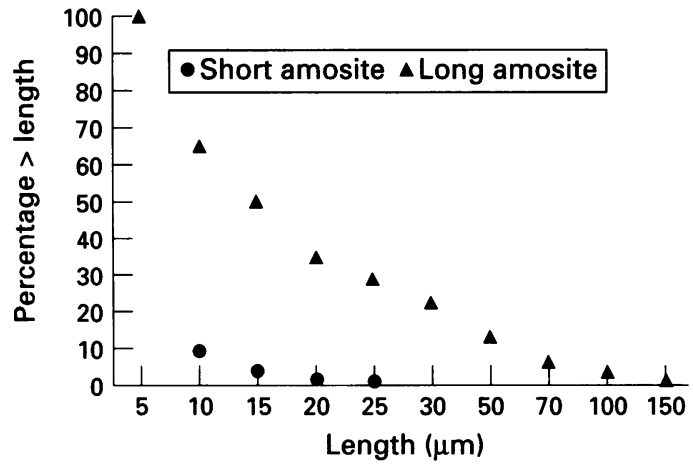

receptors on the cell surface is thought to be the recognition step that initiates phagocytosis. ${ }^{16}$ It has been proposed that cross linking of cell surface $\mathrm{Fc}$ receptors by chrysotile asbestos fibres opsonised by IgG could be the trigger for such superoxide generation, ${ }^{14}$ as the superoxide anion is known to be released outside the cell when phagocytosis of long fibres of asbestos is attempted. ${ }^{17}$

Only a few studies have included amosite asbestos in their investigations and Roney and Holian found that, in contrast to chrysotile exposure, guinea pig macrophages did not release superoxide when challenged with amosite. ${ }^{7}$ Davis and coworkers showed a difference in pathogenicity between long and short fibres of amosite. ${ }^{18}$ The same fibre samples were used by Donaldson $e t$ al to show an enhancement of inflammation dependent upon fibre length ${ }^{19}$ and greater cytokine secretion by alveolar macrophages exposed to long amosite fibres than to short fibres. ${ }^{20}$

It has been suggested that production of oxidants by leucocytes may be important in disease related to fibres, and that long and short fibres are very different in pathogenicity. The purpose of this study was to investigate the ability of both long and short fibres of amosite asbestos to stimulate production of superoxide in rat alveolar macrophages, and to determine how rat IgG might modify these responses.

\section{Materials and methods}

Cytochrome $c$ type III from horse heart, superoxide dismutase (SOD) from bovine erythrocytes, and rat IgG were from the Sigma Chemicals, Poole, Dorset. Dulbecco's phosphate buffered saline (PBS) was from Gibco, Paisley, Renfrewshire and adjusted to $\mathrm{pH} 7 \cdot 4$. All other chemicals were from BDH Chemicals, Poole, England.

A stock solution of phorbol myristate acetate (PMA) was prepared by addition of $0.5 \mathrm{ml}$ of dimethyl sulphoxide (DMSO) to $1 \mathrm{mg}$ of PMA and was frozen at $-70^{\circ} \mathrm{C}$ in $10 \mu 1$ aliquots until required. This was diluted 1:200 with PBS immediately before use. Similarly, 75000 units of SOD was made up to $1 \mathrm{ml}$ with distilled water, aliquoted, and stored as for the PMA. Rat IgG was prepared at a concentration of $5 \mathrm{mg} / \mathrm{ml}$ and frozen at $-70^{\circ} \mathrm{C}$ in $100 \mu \mathrm{l}$ aliquots. The SOD was added to reaction buffer at a concentration of $1.5 \mu \mathrm{l}$ of SOD $/ \mathrm{ml}$ of buffer for use in control tubes. The reaction buffer was freshly prepared with PBS, $1 \mathrm{mg} / \mathrm{ml}$ cytochrome $c$, and $2 \mathrm{mg} / \mathrm{ml}$ dextrose.

\section{CELLS}

Male Wistar rats were killed by a $2 \mathrm{ml}$ intraperitoneal injection of sodium phenobarbitone $(60 \mathrm{mg} / \mathrm{ml})$, and the trachea was exposed by blunt dissection. A small incision was made between the cartilagenous rings, and a blunt needle introduced and secured with fishing line. The lungs were then dissected free of the thoracic cavity and lavaged with four $10 \mathrm{ml}$ volumes of normal saline at $37^{\circ} \mathrm{C}$. After installation of the lavage fluid, the lungs were massaged gently to increase the yield of alveolar macrophages.

The isolated cells were centrifuged at $350 \times g$ for 10 minutes at $4^{\circ} \mathrm{C}$ and the cell pellets resuspended in $1 \mathrm{ml}$ of sterile PBS. Viability was checked by trypan blue exclusion and cell numbers were counted with an improved Neubauer haemocytometer. Purity was checked by prepared cytocentrifuge slides stained with Diffquick (Merz Dade, Switzerland).

\section{FIBRES}

The fibres used in this study were the long and short fibre amosite samples described extensively in previous publications. ${ }^{18-20}$ Figure 1 shows the length distribution. The diameter distributions are virtually identical. Due to the ball milling of the long fibre sample to produce the short, there was extensive comminution of fibres, such that only $37 \%$ of the short sample by mass was classified as fibre by the World Health Organisation (WHO) classification of $>5 \mu \mathrm{m}$ long, $<3 \mu \mathrm{m}$ diameter, and aspect ratio $>3: 1$.

\section{OPSONISATION OF FIBRES}

The asbestos samples were mixed with PBS at a concentration of $1 \mathrm{mg} / \mathrm{ml}$, and $50 \mu \mathrm{l}$ of rat IgG $(5 \mathrm{mg} / \mathrm{ml})$ was added. The suspensions were incubated for 30 minutes at $37^{\circ} \mathrm{C}$ with constant rotation, and spin-washed three times in PBS, at $900 \mathrm{~g}$ for 10 minutes. Naked samples (without IgG) were taken through an identical incubation and washing protocol. Pellets were resuspended at stepped suspension concentrations from $125 \mu \mathrm{g}$ to $20 \mathrm{mg} / \mathrm{ml}$ for short fibre amosite, and from 15.6 $\mu \mathrm{g}$ to $5 \mathrm{mg} / \mathrm{ml}$ for the long fibre samples. All dust samples were dispersed by passing the suspensions 10 times through a $23 \mathrm{G}$ needle attached to a $20 \mathrm{ml}$ syringe.

\section{ASSAY OF SUPEROXIDE ANIONS}

The method used was an adaptation of that previously described. ${ }^{21}$ Cell suspensions were diluted to yield $5 \times 10^{6} \mathrm{cells} / \mathrm{ml}$. The assay was carried out in duplicate with $3 \mathrm{ml}$ tubes and $0.25 \times 10^{6}$ cells/tube. Either $15 \mu 1$ of PMA or $100 \mu \mathrm{l}$ of the naked or opsonised dust suspension was used as a trigger for superoxide production. Reaction buffer containing cytochrome $c$ was added to each tube to give a final assay volume of $1.5 \mathrm{ml}$. Tubes with no dust or PMA were also set up as a check for 
any endogenous superoxide production by untriggered cells.

The tubes were incubated and shaken at $37^{\circ} \mathrm{C}$ in a water bath for one hour before centrifugation at $900 \mathrm{~g}$ for five minutes to remove particulates. (Optimum incubation times were assessed by serial incubation studies from zero to two hours; data not shown).

The supernatant extinctions were determined at both $550 \mathrm{~nm}$ and $468 \mathrm{~nm}$ against a PBS blank, and the difference in these readings converted to concentration of superoxide anions/million cells. An extinction coefficient of $0.021 \mu \mathrm{M}$ was used for cytochrome $c$.

The complete experimental run was also carried out with tubes that contained the prepared buffered SOD substituted for normal reaction buffer. To correct for any reduction of cytochrome $c$ independent of superoxide

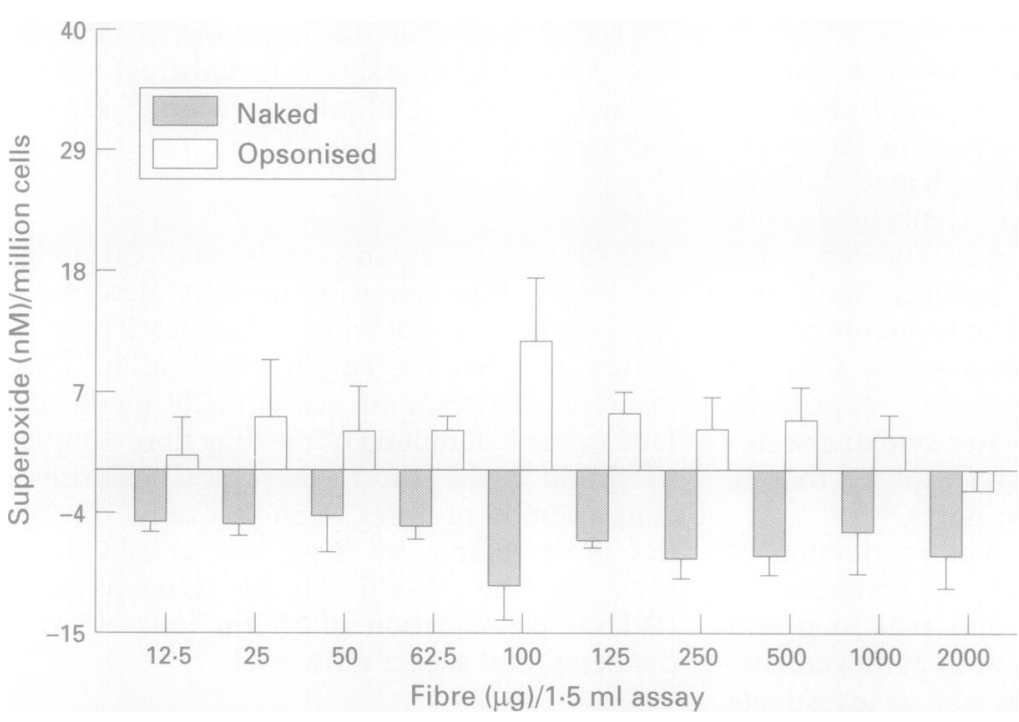

Figure 2 Production of superoxide anions by isolated rat alveolar macrophages treated with naked short fibre amosite asbestos or those opsonised by IgG. Results are shown compared with background. Each bar represents the mean (SEM) of at least three separate experiments with duplicate samples.

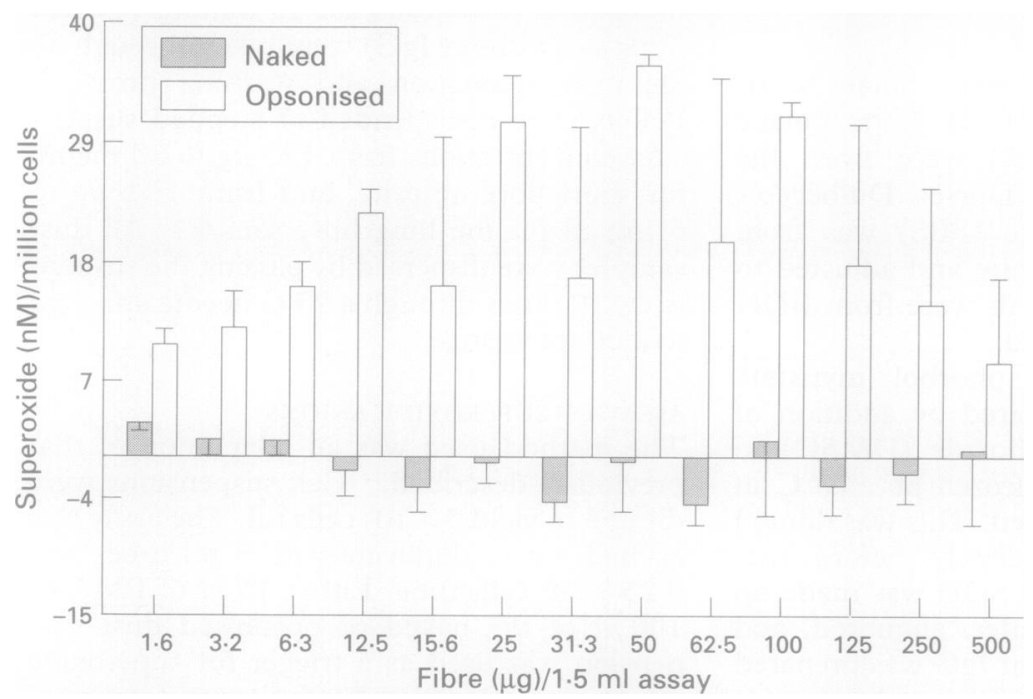

Figure 3 Production of superoxide anions by isolated rat alveolar macrophages treated with naked long fibre amosite asbestos or those opsonised by IgG. Results are shown compared with background. Each bar represents the mean (SEM) of three separate experiments with duplicate samples. anions, superoxide production was assessed as only the reduction in cytochrome $c$ inhibitable by SOD. This was measured by subtracting the control results from those obtained from the samples. Overall results are expressed as $\mathrm{nM}$ of superoxide produced/million cells

\section{RADIOIODINATION OF PROTEIN}

To investigate potential differences in the adsorption of protein by both long and short amosite fibres, the complete opsonisation procedure was repeated with ${ }^{125}$ I labelled IgG. Rat immunoglobulin was iodinated with a procedure previously described, ${ }^{22}$ and the unbound ${ }^{125} \mathrm{I}$ separated from ${ }^{125} \mathrm{I}-\mathrm{IgG}$ conjugate by passing through a PD-10 column.

OPSONISATION OF DUSTS WITH ${ }^{125} \mathrm{I}-\mathrm{IgG}$

Dusts were mixed with PBS to a concentration of $1 \mathrm{mg} / \mathrm{ml}$, and $0.5 \mathrm{ml}$ of rat ${ }^{125} \mathrm{I}-\mathrm{IgG}$ $(5 \mu \mathrm{g} / \mathrm{ml})$ was added. The mixtures were incubated for 30 minutes at $37^{\circ} \mathrm{C}$ with constant rotation, and were spin-washed three times in PBS, at $900 \mathrm{~g}$ for 10 minutes. Opsonised dust pellets were resuspended at a concentration of $5 \mathrm{mg} / \mathrm{ml}$ and $100 \mu \mathrm{l}$ aliquots were read in a gammacounter.

STATISTICAL ANALYSES

All experiments were repeated at least three times under identical conditions. Results of repeat experiments were analysed by analysis of variance, with the general linear model in the Minitab statistical computer program (Minitab, 1989). Effects of treatment are expressed as variance ratio $(F)$ statistics, with $\mathrm{P}$ values. Data for the binding of labelled IgG to fibres, were log transformed before analysis.

\section{Results}

The average production of superoxide by unstimulated macrophages was $17 \mathrm{nM} / \mathrm{mil}$ lion cells; this was presumed to be a result of stimulation by contact with the plastic assay tubes. Stimulation by PMA generated an average of $113.7 \mathrm{nM}$ of superoxide/million cells. The results are expressed as the mean of duplicate tubes in at least three separate experiments, with subtraction of the unstimulated control values.

\section{SHORT FIBRES}

Figure 2 shows production of superoxide anions by rat alveolar macrophages when exposed to different doses of both naked (unopsonised), and IgG-opsonised, short fibre amosite asbestos. Macrophages challenged with naked fibres produced less superoxide than unstimulated cells (mean (SD) 6.5 (1.99) $\mathrm{nM}$ less than background production). Opsonised fibres induced significant stimulation (mean (SD) $4 \cdot 1$ (3.4) $\mathrm{nM}$ over background). The ANOVA showed a significant effect of opsonisation: $F=71 \cdot 83, \mathrm{P}<0.001$.

\section{LONG FIBRES}

With long fibre amosite (fig 3), the magnitude of the macrophage response was slightly suppressed compared with a background of 


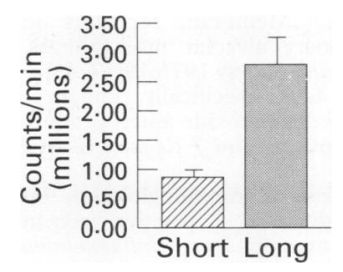

Figure 4 Binding of ${ }^{125} I$ labelled IgG to samples of short and long fibre amosite asbestos. Bars show mean (SEM) of four separate experiments. naked long fibres (mean (SD) $0.8(2.45) \mathrm{nM}$ less than background). Opsonised long fibres, however, produced a substantial stimulation of superoxide release with a mean (SD) of 19.4 (8.46) $\mathrm{nM}$ more than background. The ANOVA showed a significant effect of opsonisation: $F=68 \cdot 27, \mathrm{P}<0.001$.

When fibre length was considered across all experiments there was an evident and highly significant effect, $F=14.34, P<0.001$ that confirmed the increased stimulatory potential of long fibre amosite.

Figure 4 shows the amount of radiolabelled opsonin binding to the short and long fibre samples. It is clear that the short fibres bound much less opsonin than the long fibre sample: $F=18 \cdot 18, \mathrm{P}<0.001$.

\section{Discussion}

Our study has shown that, in an unopsonised state, neither long nor short fibres of amosite asbestos were effective in stimulating rat alveolar macrophages to release superoxide anions. In fact, unopsonised short amosite seemed to inhibit superoxide release, although this effect was small. There was no obvious toxicity to the alveolar macrophages with any treatment, as assessed by the percentage of total cellular lactate dehydrogenase released into the culture medium during incubation (data not shown). This suggests that short amosite may be capable of inhibiting the membrane NADPH oxidase. This remains speculative, however, and was not pursued.

The dramatic enhancement of release of superoxide anions found when the long fibre amosite was opsonised with IgG, confirmed the greatly increased biological activity after opsonisation, ${ }^{11} 141520$ presumably through an increase in the second messenger system of the macrophage induced by $\mathrm{Fc}$ receptors. ${ }^{20}$

Of the 13 dust treatments in the dose response from unopsonised long amosite fibres, five showed slight stimulation, two showed virtually no effect, and six showed a slight decrease in superoxide production. We deduce from this that the unopsonised long amosite had no net effect on superoxide release.

Even opsonised short amosite consistently provoked a modest oxidative burst. All data were expressed as release of superoxide anions per unit mass, as very little of the short amosite was present as WHO defined fibres ( $>5 \mu \mathrm{m}$ long, $<3 \mu \mathrm{m}$ diameter with an aspect ratio $>3: 1) .{ }^{18}$ Our study confirms the importance of long fibres in the mediation of biological effects, as the long fibres were substantially more able to stimulate superoxide release than the short. It seems likely that the activity that was present in the short fibre sample was mediated by the few fibres that were longer than $5 \mu \mathrm{m}$. $^{18}$

One of the most distinctive aspects of the biological effects induced by fibres is the difference that can be found both between dusts and between different samples of the same dust. Some studies indicate that the variations in response reflect the physical characteristics of the minerals involved, such as shape, diameter, fibre length, or surface area, ${ }^{4823}$ whereas others have implicated the surface charge or chemical composition. ${ }^{1724-28}$

The increased biological activity of the long fibre sample in this study could be explained by increased binding of opsonic IgG to the fibre surface as, at equal mass, the long fibre asbestos bound threefold more IgG than the short fibres. Earlier studies with these two samples of amosite suggested that the short fibres (obtained by ball milling the long fibres) were identical elementally, crystallographically, and chemically to the long fibres. No previous effort was made to compare the surface reactivity of the two samples. Our study has shown that the surface of the short fibres is different from that of the long fibres in terms of ability to bind the opsonin IgG. Indeed, the short fibres might have been predicted to bind more protein than the long, because of the increased surface area engendered by the extra number of ends. The process of ball milling could have contaminated the surface of the short fibre sample, or exposed different crystal faces, which may differ from the surfaces of the long sample.

Previous work with this amosite has shown increased pathogenicity, ${ }^{18}$ inflammatory potential, ${ }^{19}$ and ability to cause release of tumour necrosis factor, ${ }^{20}$ in the long fibre sample compared with the short. Our study suggests that an additional factor, surface reactivity, could be important in mediating the increased activity of the long fibre sample, over and above its greater average length. Ball milling is a process that might be expected to cause changes in surface reactivity due to the violent interaction between the fibres and the components of the ball mill during the process of milling. To obtain long and short amosite samples that are similar, a less energetic method would seem to be necessary.

Several groups have attempted to modify the surface of asbestos fibres to alter their bioactivity in vitro and, as fibres deposited in the lung are immediately exposed to pulmonary surfactant, the opsonins present in alveolar lining fluid have attracted much attention. ${ }^{1114152029}$ A normal component of lung lining fluid, IgG, ${ }^{30} 31$ is increased 10-fold in rats exposed to chrysotile asbestos. ${ }^{32}$ Our study confirms that fibres that deposit in the lung fluid will increase in ability to generate reactive oxygen species, and to become more pathogenic. Furthermore, deposition in the lungs of people with existing inflammation from any cause, could lead to more biologically active fibres, than deposition in the lungs of normal people with normal concentrations of pulmonary IgG.

Previous studies have shown that proteins (including components of complement, ${ }^{33}$ immunoglobulin, and other globular proteins $^{34}$ ) bind to the surface of asbestos fibres. There is evidence that there could be differences in the site of adsorption that lead to competition between proteins for access to binding sites when fibres are placed in a solution of different proteins. ${ }^{20}$ Further work is 
required to investigate the lung lining fluid, which is a complex mixture of protein and lipid, ${ }^{35}$ to find the relative importance of opsonisation in vivo.

No work was done to characterise the mechanism of increased release of superoxides found in our study with opsonised long fibre asbestos. We presume that the protein kinase C system of the cell is involved, as shown for other similar activities of opsonised fibres, such as release of superoxide anions ${ }^{1+}$ and release of tumour necrosis factor. ${ }^{20}$

In conclusion, our study has confirmed the importance of opsonisation in modulating the biological activity of fibres at the cellular level, but it has also pointed out important differences in binding of a protein to samples of fibres previously considered to be identical apart from length. The differential binding may explain the biological activity of the fibre. This factor needs to be taken into account when fibres are compared, as binding of biological molecules in vivo may be an important modifying factor in the pathological processes initiated by fibres.

1 Kamp DW, Graceffa P, Pryor WA, Weitzman SA. The role of free radicals in asbestos-induced diseases. Free Radic Biol Med 1992;12:293-315.

2 Weitzman SA, Graceffa P. Asbestos catalyses hydroxyl and superoxide radical generation from hydrogen peroxide. Arch Biochem Biophys 1984;228:373-6.

3 Freeman BA, Crapo JD. Biology of free radicals and tissue injury. Lab Invest 1982;47:412-26.

4 Hansen K, Mossman BT. Generation of superoxide from alveolar macrophages exposed to asbestiform and nonfibrous particles. Cancer Res 1987;47:1681-6.

5 Mossman BT, Marsh JP, Shatos MA, Doherty J, Gilbert $\mathrm{R}$, Hill $\mathrm{S}$. Implication of oxygen species as second messengers of asbestos toxicity. Drug Chem Toxicol 1987;10:157-80.

6 Mossman BT, Light W, Wei E. Asbestos: mechanisms of toxicity and carcinogenicity in the respiratory tract. Ann Rev Pharmacol Toxicol 1983;23:595-615.

7 Roney PL, Holian A. Possible mechanism of chrysotile asbestos-stimulated superoxide anion production in
guinea pig alveolar macrophages. Toxicol Appl Pharmacol guinea pig alveolar

8 Archer VE. Carcinogenicity of fibers and films: a theory. Med Hypotheses 1979;5:1257-60

9 Kalla B, Hamilton RF, Scheule RK, Holian A. Role of extracellular calcium in chrysotile asbestos stimulation of alveolar macrophages. Toxicol Appl Pharmacol 1990; 104:130-8.

10 Case BW, Ip MPC, Padilla M, Kleinerman J. Asbestos effects on superoxide production: an in vitro study of hamster alveolar macrophages. Environ Res 1986;39: 299-306.

11 Perkins RC, Scheule RK, Holian A. In vitro bioactivity of asbestos for the human alveolar macrophage and its modification by IgG. Am $\mathcal{f}$ Respir Cell Mol Biol 1991; 4:532-7

12 Reynolds HY, Atkinson JP, Newball HH, Frank MM Receptors for immunoglobulin and complement on human alveolar macrophages. ff Immunol 1975;114: 1813-9
13 Daughaday CC, Douglas SD. Membrane receptors on rabbit and human pulmonary alveolar macrophages. Fournal of the Reticuloendothelial Society 1976;19:37-45.

14 Scheule RK, Holian A. IgG specifically enhances chrysotile asbestos-stimulated superoxide anion production by the alveolar macrophage. Am 7 Respir Cell Mol Biol 1989;1:313-8.

15 Nyberg P, Klockars M. Effect of immunoglobulins on mineral dust-induced production of reactive oxygen
metabolites by human macrophages. Inflammation metabolites by

16 Griffin FM, Griffin JA, Silverstein SC. Studies on the mechanism of phagocytosis. F Exp Med 1976;144:788

17 Goodglick LA, Kane AB. Role of reactive oxygen metabolites in crocidolite asbestos toxicity to mouse macrophages. Cancer Res 1986;46:5558-66.

18 Davis JMG, Addison J, Bolton RE, Donaldson K, Jones $\mathrm{AD}$, Smith $\mathrm{T}$. The pathogenicity of long versus short fibre samples of amosite asbestos administered to rats by inhalation and intraperitoneal injection. British foumal of Experimental Pathology 1986;67:415-30.

19 Donaldson K, Brown GM, Brown DM. Inflammation generating potential of long and short fibre amosite generating potential of long and short fibre

20 Donaldson K, Li Xiao Yang, Dogra S, Miller B, Brown G Asbestos-stimulated tumour necrosis factor release from alveolar macrophages depends on fibre length and opsonisation. $\mathcal{F}$ Pathol 1992;168:243-8.

21 Johnstone RB. Secretion of superoxide anion. In: Adams DO, Edelson PJ, Koren $\mathrm{H}$, eds. Methods for studying mononuclear phagocytes. New York: Academic Press, 1981:489-97.

22 McConahey PJ, Dixon FJ. Radioiodination of proteins by the use of the chloramine-T method. Methods Enzymol 1980;70:210-6.

23 Kaw JL, Tilkes F, Beck EG. Reaction of cells cultured in vitro to different asbestos dusts of equal surface area but different fibre length. British fournal of Experimental Pathology 1982;63:109-15.

24 Light WG, Wei ET. Surface charge and asbestos toxicity. Nature 1977;265:537-9.

25 Vallyathan V, Xianglin S, Delal N, Irr W, Castranova V. Generation of free radicals from freshly fractured silica dust. Potential role in acute silica-induced lung injury. Am Rev Respir Dis 1988;138:1213-9.

26 Dalal NS, Suryan MM, Vallyathan V, Green FHY, Jafari $\mathrm{B}$, Wheeler $\mathrm{R}$. Detection of reactive free radicals in fresh coal mine dust and their implication for pulmonary injury. Ann Occup Hyg 1989;33:79-84.

27 Kennedy TP, Dodson R, Rao NV, Ky H, Hopkins C, Baser M, Tolley E, Hoidal JR. Dusts causing pneumoconiosis generate $\mathrm{OH}$ and produce hemolysis by acting as Fenton catalysts. Arch Biochem Biophys 1989;269 359-64.

28 Lund LG, Aust AE. Iron-catalysed reactions may be responsible for the biochemical and biological effects of asbestos. Biofactors 1991;3:83-9.

29 Brown RC, Carthew P, Hoskins JA, Sara E, Simpson CF Surface modification can affect the carcinogenicity of asbestos. Carcinogenesis 1990;11:1883-5.

30 Reynolds HY. Immunoglobulin G and its function in the human respiratory tract. Mayo Clin Proc 1988;63: $161-74$

31 Reynolds HY. Pulmonary host defenses: state of the art Chest 1989;95:223s-30s.

32 Tetley TD, Richards RJ, Harwood JL. Changes in pulmonary surfactant and phosphotidylcholine metabolism in rats exposed to chrysotile asbestos dust. Biochem 7 1976;166:323-9.

33 Hasselbacher P. Binding of immunoglobulin and activation of complement by asbestos fibers. $\mathcal{F}$ Allergy Clin Immunol 1979;64:294-8.

34 Desai R, Richards RJ. The adsorption of biological macromolecules by mineral dusts. Environ Res 1978;16: 449-64.

35 Hunninghake GW, Gadek JE, Kawanami O, Ferrans VI, Crystal RG. Inflammatory and immune processes in the human lung in health and disease: evaluation by bronchoalveolar lavage. Am f Pathol 1979;97:149-206. 